$0 \quad$ Authors Queries

Journal: International Journal of Remote Sensing

Paper: 178374

Title: Land cover classification using multi-temporal MERIS vegetation indices

Dear Author

During the preparation of your manuscript for publication, the questions listed below have arisen. Please attend to these matters and return this form with your proof. Many thanks for your assistance

\begin{tabular}{|l|l|l|}
\hline $\begin{array}{l}\text { Query } \\
\text { Reference }\end{array}$ & Query & Remarks \\
\hline 1 & $\begin{array}{l}\text { Beneditti - please check spel- } \\
\text { ling as Refs show Benedetti } \\
\text { (also follow through other cita- } \\
\text { tions in text). }\end{array}$ & \\
\hline 2 & $\begin{array}{l}\text { Townsend - please check as } \\
\text { Refs show Townshend. }\end{array}$ & \\
\hline 3 & $\begin{array}{l}\text { estimated - OK to change to } \\
\text { calculated/gauged/assessed? }\end{array}$ & \\
\hline 4 & $\begin{array}{l}\text { WiDNR, 1998 - please supply } \\
\text { date accessed. }\end{array}$ & \\
\hline
\end{tabular}




\title{
Land cover classification using multi-temporal MERIS vegetation indices
}

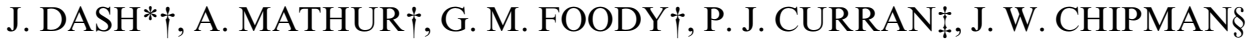 \\ and T. M. LILLESAND $\S$
}

$\dagger$ School of Geography, University of Southampton, Southampton, SO17 1BJ, UK

†Office of the Vice-Chancellor, Bournemouth University, Talbot Campus, Fern Barrow, Poole, BH12 5BB, UK

$\S$ Environmental Remote Sensing Center, University of Wisconsin-Madison, Madison, WI 53706, USA

The spectral, spatial, and temporal resolutions of Envisat's Medium Resolution Imaging Spectrometer (MERIS) data are attractive for regional- to global-scale land cover mapping. Moreover, two novel and operational vegetation indices derived from MERIS data have considerable potential as discriminating variables in land cover classification. Here, the potential of these two vegetation indices (the MERIS global vegetation index (MGVI), MERIS terrestrial chlorophyll index (MTCI)) was evaluated for mapping eleven broad land cover classes in Wisconsin. Data acquired in the high and low chlorophyll seasons were used to increase inter-class separability. The two vegetation indices provided a higher degree of inter-class separability than data acquired in many of the individual MERIS spectral wavebands. The most accurate landcover map $(73.2 \%)$ was derived from a classification of vegetation index-derived data with a support vector machine (SVM), and was $4.4 \%$ more accurate than the corresponding map derived from a classification using the data acquired in the original spectral wavebands.

\section{Introduction}

Land cover maps provide key environmental information needed for environmental understanding, resource management, and policy development at a range of spatial scales (Cihlar 2000, Latifovic et al. 2004, Treitz and Rogan 2004). Remote sensing has considerable potential for the provision of land cover maps but the accuracy of the maps derived is often viewed as insufficient (Wilkinson 1996, Foody 2002). There are many factors responsible for this situation, including the nature of classes being studied, the properties of the sensing system used to acquire the imagery, and also the techniques used to extract thematic information from the imagery (Steele 2000, Foody 2002, Pal and Mather 2003). Despite considerable recent research into land cover classification, the accuracy with which land cover has been mapped from remotely sensed data often remains low, and there does not appear to be an upward trend in accuracy over time. Wilkinson (2005) highlighted the need for further advances if the full potential of remote sensing for land cover is to be realized.

*Corresponding author. Email: jadu@soton.ac.uk 
The growing need for land cover information has driven developments in sensing technologies, as well as advances in methods to extract information from remotely sensed data. Research over the past decade has, for example, focused on ways to increase the accuracy of thematic information extraction from remotely sensed data (Benediktsson et al. 1990, Friedl and Brodley 1997, Foody and Mathur 2004), often making use of contemporary sensing systems with enhanced spectral, spatial, and radiometric properties. Much research has also addressed the potential benefits to be derived from the inclusion of additional information such as (1) image texture, context, and ancillary information (e.g. soil, topography), and (2) waveband transformations such as vegetation indices (Beneditti et al. 1994, Krishnaswamy et al. 2004, Li and Moon 2004, Mather 2004) into the classification. This article focuses on the use of vegetation indices as discriminating variables for land cover classification.

Vegetation indices, empirical formula derived using reflected radiance in two or more wavelengths, have been used widely to indicate and estimate biophysical variables. Vegetation indices may be used also to enhance the spectral contrast between vegetated and non-vegetated land cover classes, and so may be useful as discriminating variables in classification applications. The most commonly used vegetation indices are the normalized difference vegetation index (NDVI) and simple ratio (SR) (Gaston et al. 1994, Myneni et al. 1995, Lobo et al. 1997). However, vegetation indices have been developed that are relatively insensitive to confounding variables such as soil background, sun-sensor angular geometry, and the atmosphere. For example, widely used indices include the perpendicular vegetation index (PVI) (Richardson and Wiegand 1977), weighted distance vegetation index (WDVI) (Clevers 1988), soil adjusted vegetation index (SAVI) (Huete 1988), transformed soil adjusted vegetation index (TSAVI) (Baret and Guyot 1991), atmospherically resistant vegetation index (ARVI) (Kaufman and Tanré 1992), and the global environmental monitoring index (GEMI) (Pinty and Verstraete 1992). Although often used to indicate and estimate biophysical variables (Tucker et al. 1985), vegetation indices have also often been used as discriminating variables in image classification (e.g. Justice et al. 1989, Lloyd 1990, Hill and Foody 1994, Beneditti et al. 1994, Achard and Estreguil 1995).

The NDVI is the most widely used of the vegetation indices for classification applications (Lloyd 1990, Myneni et al. 1995, Li and Moon 2004). For example, using NDVI data, Running et al. (1995) present a decision tree classification based on the permanence of above-ground biomass, longevity of leaves, and leaf type. Critically, the use of a vegetation index can yield a classification that is more accurate than one derived from the data used in its calculation (Anderson et al. 1993, Nemani et al. 1993, Hirata et al. 2001). This feature, together with the ready availability of NDVI data in major archives (e.g. Smith et al. 1997), has led to the NDVI being used widely as a discriminating variable in image classification. Indeed, the NDVI derived from a variety of different sensors has been used to classify vegetated terrain at scales ranging from the local to global (Benedetti et al. 1994, Lobo et al. 1997, Hansen et al. 2000, Han et al. 2004). The NDVI is, for example, at the core of major global land cover mapping programmes (e.g. Loveland et al. 2000). Typically, the data used are a time series of NDVI images that provide a measure of phenological variability in space and time, which can facilitate inter-class discrimination (Tucker et al. 1985, DeFries and Townsend 1994). However, the use of the NDVI to classify vegetation has some major limitations, such as a relative 
0 insensitivity to canopy structural variables and background reflectance. Additionally, the NDVI is insensitive to very high and very low chlorophyll content. Chlorophyll is a key biochemical variable, and plant chlorophyll content varies with vegetation type (Peterson et al. 1988, Smith and Curran 1992, Clark 1995, Curran et al. 2001). For example, deciduous trees have higher chlorophyll content than coniferous trees. Not only is the chlorophyll content different for dissimilar vegetation types at a particular time, but also the variation in chlorophyll content for a growing season depends on vegetation type. This indicates that knowledge of chlorophyll content in space and time may enhance class separability and the production of accurate land cover maps.

There are many methods available for the estimation of leaf chlorophyll content (Mariotti et al. 1996, Datt 1998, Gitelson and Merzlyak 1998) and canopies (Peterson et al. 1988, Curran et al. 1995, Pinar and Curran 1996, Daughtry et al. 2000, O’Neill et al. 2002) using remote sensing. These methods are based on the use of data acquired in narrow spectral wavebands in the red and near-infrared (NIR) 15 region. The availability of such narrow bandwidth data has increased recently with the launch of spaceborne spectrometers (Rast et al. 1999, Curran and Steele 2005). Spaceborne spectrometers provide data over a range of spatial and temporal scales that can be used to map vegetation distribution (Huete et al. 2002), estimate vegetation amount (Gobron et al. 2003), and monitor the vegetation condition (Dash and Curran 2004).

The Medium Resolution Imaging Spectrometer (MERIS), part of the European Space Agency's (ESA) Envisat mission, operates in 15 programmable wavebands (2.5-20 nm wide) in the 390-1040 nm region, with spatial resolutions of $300 \mathrm{~m}$ and $1200 \mathrm{~m}$ (figure 1). Because of its high radiometric resolution, relatively fine spectral resolution, moderate spatial resolution, and three-day repeat cycle, MERIS potentially is a valuable sensor for the measurement and monitoring of terrestrial

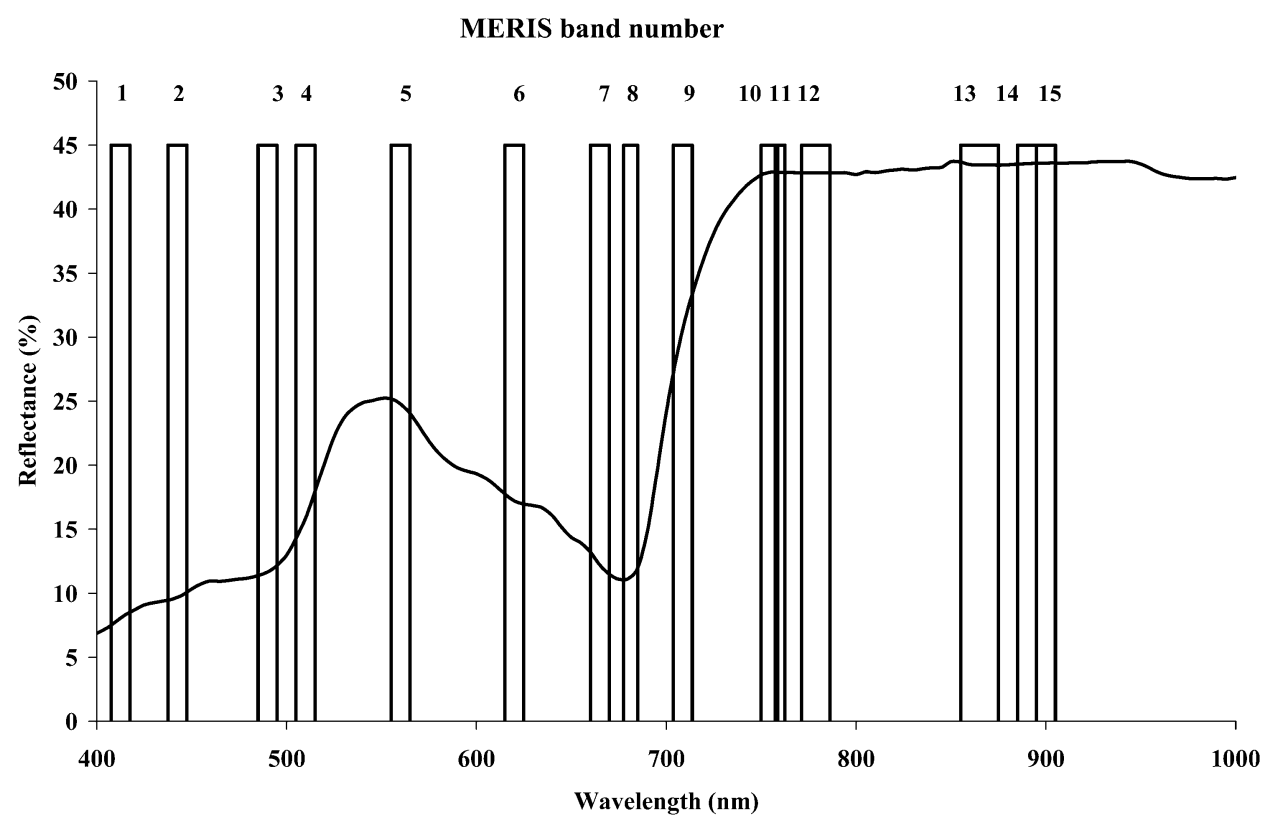

Figure 1. Location of the MERIS wavebands overlain on a model vegetation spectrum. 
0 environments at regional to global scales (Rast et al. 1999, Verstraete et al. 1999, Curran and Steele 2005).

MERIS primary data products include calibrated instantaneous radiance estimates in each waveband at both full $(300 \mathrm{~m})$ and reduced $(1200 \mathrm{~m})$ spatial resolution. The secondary products include a number of geophysical and biophysical products over land, ocean, and atmosphere. MERIS data are available at three levels of processing. Level 1 data are top of the atmosphere radiances, level 2 data are atmospherically corrected top-of-canopy reflectances, as well as geophysical and biophysical products (e.g. MERIS global vegetation index (MGVI); Gobron et al. 1999), and level 3 data are derived products (e.g. mosaic of fraction of photosynthetically absorbed radiation (fPAR)). Of relevance here is that the level 2 MERIS data products include two vegetation indices: the MGVI and the MERIS terrestrial chlorophyll index (MTCI; Dash and Curran 2004).

The MGVI uses information from the blue, red, and near-infrared (NIR) part of the spectrum (Gobron et al. 1999). The information in blue wavelengths (MERIS waveband 2) is used to mask out pixels contaminated by atmospheric effects, with the index calculated for all other pixels. The normalized red (MERIS waveband 8) and NIR (MERIS waveband 13) wavebands are used to derive information on vegetation amount and structure. The magnitude of the MGVI has a near linear positive relationship with fPAR, which, in turn, is related positively to LAI.

The MTCI is derived from data in red and NIR wavebands centred at $681.25 \mathrm{~nm}$, $708.75 \mathrm{~nm}$, and $753.75 \mathrm{~nm}$ (corresponding to wavebands 8, 9, and 10 of the MERIS standard band setting, figure 1), and produce a value that is related to the relative position of the red edge (Dash and Curran 2004). In comparison with the red edge position, the MTCI is simpler to calculate; more sensitive to high values of chlorophyll content and less sensitive to spatial resolution and atmospheric effects.

The aim of this article is to evaluate the potential of MERIS data, and especially the two vegetation index products (MERIS VI dataset), for land cover mapping. A key feature of the work is to determine if vegetation indices could be used to map land cover at least as accurately as a set of individual MERIS bands (MERIS spectral dataset). This would be advantageous, as it would reduce the number of discriminating variables in the analysis (which should reduce the size of the training set needed, and so the cost of undertaking a classification), as well as allowing researchers to exploit readily available data products.

\section{MERIS vegetation indices}

The study was based on the premise that the relationship between chlorophyll concentration and vegetation type varies with time. For example, vegetation with a large temporal range in chlorophyll concentration includes broadleaf forests and crops, while shrubs and pasture, in most cases, have a low chlorophyll range. The range in chlorophyll concentration over a growing season is expected to vary between different land cover classes and is associated with the phenology of the vegetation types. For example, deciduous trees have a higher variation in chlorophyll concentration than coniferous trees. This variation in chlorophyll concentration may be influenced also by geographical location. The range in chlorophyll concentration is, therefore, a function of time, space, and land cover type. 
0 The MGVI is related to biophysical variables such as LAI and is calculated from:

$$
\mathrm{MGVI}=\mathrm{g} 0(\rho \mathrm{R} 681, \rho \mathrm{R} 865)
$$

where $\mathrm{g} 0$ is the generic function (Verstraete and Pinty 1996), and $\rho \mathrm{R} 681$ and $\rho \mathrm{R} 865$ are rectified bidirectional reflectance values in MERIS bands centred at $681.25 \mathrm{~nm}$ and $865 \mathrm{~nm}$ (Gobron et al. 1999).

The MTCI is related to biochemical variables such as chlorophyll content and is the ratio of the difference in reflectance between wavebands 10 and 9 and the difference in reflectance between wavebands 9 and 8 of the MERIS standard band setting

$$
\text { MTCI }=\frac{\mathrm{R}_{753.75}-\mathrm{R}_{708.75}}{\mathrm{R}_{708.75}-\mathrm{R}_{681.25}}
$$

where the subscripts indicate either waveband number or the centre wavelength of the waveband in nm. The MTCI is positively related to the total chlorophyll content of vegetation, which in turn is a product of the chlorophyll concentration (amount of chlorophyll per unit area) and LAI. Consequently, the ratio MTCI/MGVI is approximately equal to chlorophyll concentration

$$
\text { Chlorophyll concentration } \approx \frac{\text { MTCI }}{\text { MGVI }}
$$

The temporal variation in chlorophyll concentration of vegetation may provide a valuable discriminating variable for mapping land cover. This variation in chlorophyll concentration can be estimated by subtracting chlorophyll concentration estimated in the low chlorophyll season from that estimated in the high chlorophyll season. The ideal dates of MERIS data acquisition for land cover classification should, therefore, be drawn from both the high and low chlorophyll seasons.

\section{Data and methods}

The study area comprised part of the state of Wisconsin, USA, where imagery acquired in late July and mid-September would represent high and low chlorophyll seasons, respectively. However, suitable cloud-free MERIS data were unavailable and so cloud-free MERIS data (spatial resolution of $300 \mathrm{~m}$ ) acquired on 18 August 2003 and 20 September 2003 were used to represent a period late in the high and early in the low chlorophyll season, respectively (figure 2). Although not ideal dates, the first lies near the end of the normal growing season, while the second corresponds to the typical date of the first frost in the fall for the study area. Thus, although not widely separated in time, the two sets of imagery provided representations of the land cover at times when the chlorophyll condition would be expected to differ markedly.

The reference land cover dataset used in this work was the Wisconsin Initiative for Statewide Cooperation on Landscape Analysis and Data (WISCLAND) land cover map (WiDNR 1998). The WISCLAND land cover map was derived from the classification of Landsat Thematic Mapper (TM) data acquired during the mid 1990s (Reese et al. 2002). Although it is based on data acquired nearly ten years prior to that of the MERIS data used in this study, the land cover in the study area was relatively stable in this period, except for gradual expansion of urban areas, which was addressed by excluding such regions from the analysis when extracting 


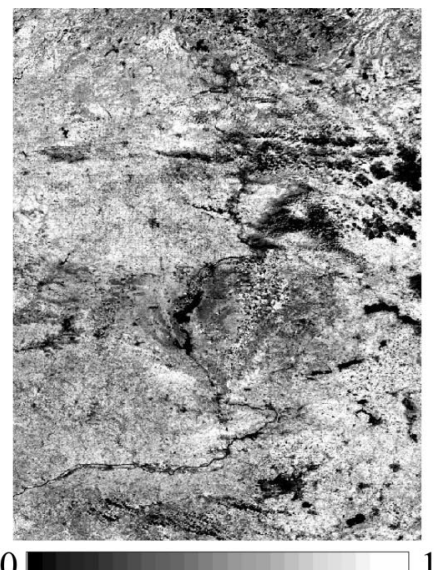

0

(a)

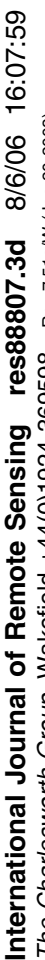

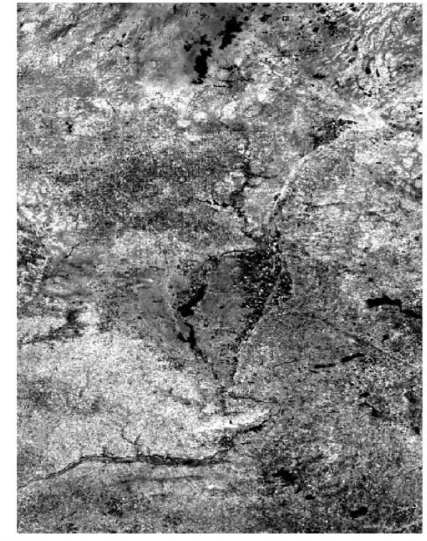

0

(c)

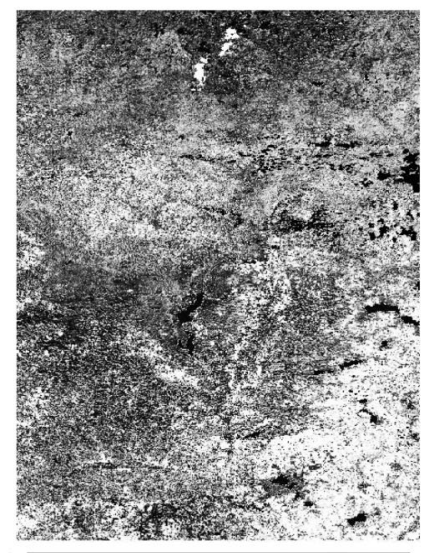

()

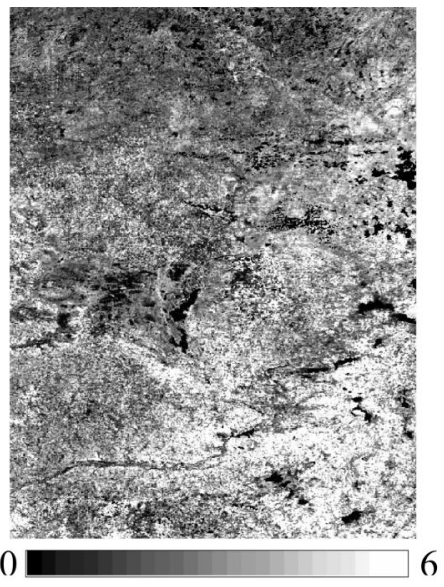

(b)

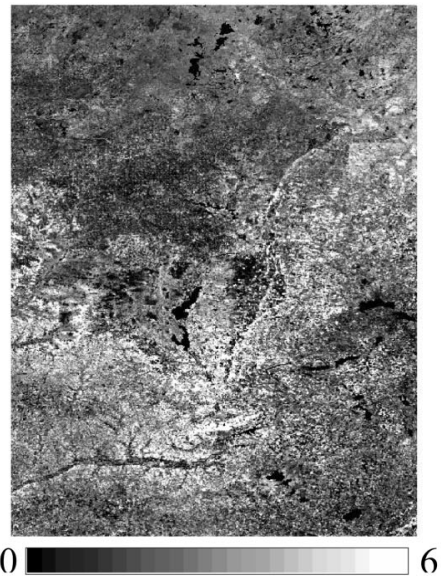

(d)

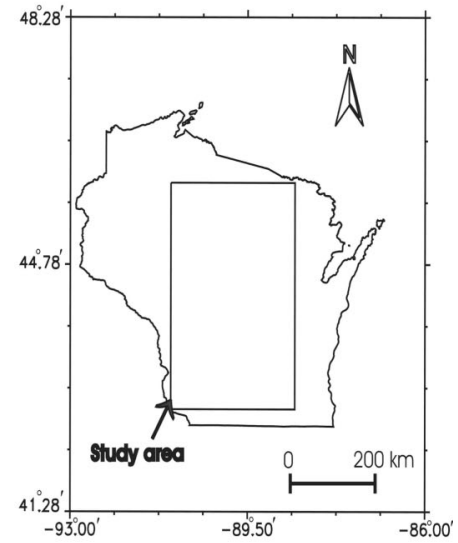

15

(e)

Figure 2. Vegetation index based data and test site location. (a) MGVI in August; (b) MTCI in August; (c) MGVI in September; $(d)$ MTCI in September; $(e)$ chlorophyll range; and $(f)$ location of test site in the State of Wisconsin. 
0 Table 1. Land cover classes and number of pixels extracted from each class for analyses. Note that the Agricultural land I category contains vegetation types present in both August and September (e.g. corn) and Agricultural land II contains classes that had been harvested by September (e.g. forage crops).

Land cover class Number of pixels

Urban

Agricultural land-I 94

Agricultural land-II

Grassland

70

Coniferous forest

98

Mixed forest

104

Deciduous forest

92

Water

Wetland

118

Forested wetland

102

Shrubland

64

15 Total

962

data from the imagery. Additionally, the WISCLAND dataset is the finest spatial resolution, most accurate and most categorically detailed land cover dataset available for the state (Lillesand et al. 1998, Reese et al. 2002). The WISCLAND dataset comprised seven classes at Anderson level I and 24 classes at Anderson level II/III. The WISCLAND data had an overall accuracy of $94 \%$ for Anderson level I upland classes (developed land, cultivated land, grassland, woody land, bare land, tundra, and snow/ice), 77\% for level II/III upland classes, and $84 \%$ for level II/III wetland classes (WiNDR 1998). For this study, the Anderson level I set of classes was deemed too generalized, while the Anderson level II/III classes too detailed for mapping from MERIS data with a $300 \mathrm{~m}$ spatial resolution. The WISCLAND detailed land cover classes were, therefore, merged to produce a generalized land cover map depicting a set of land cover classes that potentially could be classified using MERIS data (table 1) and represent all major vegetation types in the state.

Given that the ground data had a fine spatial resolution $(30 \mathrm{~m})$ relative to the MERIS data to be classified, and the proportion of mixed pixels in an image is related positively to pixel size, action was taken to ensure that only pure MERIS pixels were selected for analysis. Training and testing data were, therefore, extracted from large homogeneous sites for each of the classes to ensure pixel purity. In total, 962 MERIS pixels were extracted for further analysis, with the relative abundance of the classes within the test site reflected in the number of pixels derived for each class. The data for each class were divided randomly into equally sized training and testing sets.

Classifications were undertaken using the data acquired in the MERIS spectral wavebands directly and the MERIS vegetation indices. Due to a processing problem, ESA was unable to provide data in MERIS wavebands 11 and 15, but data acquired in all other wavebands were available and included in the analyses. For the classifications using the MERIS spectral dataset, a feature selection analysis was used to reduce the size of the dataset by removing potentially uninformative wavebands. This feature selection was based on a stepwise discriminant analysis applied to the training dataset. Wilks' lambda was used here to select the most discriminating set of the 13 MERIS spectral wavebands for use in the classification. 
Wilks' lambda is used to test whether there are differences between the means of identical groups of subjects on a combination of dependent variables. The Wilks' lambda coefficient was inversely related to the discriminatory power of the variables input to the analysis. For comparative purposes, the NDVI was also calculated for both image datasets and the separability of the classes in the resulting products assessed with Wilks' lambda. The NDVI was not, however, included in the classification as attention was focused on the potential of the MERIS vegetation index products as discriminating variables.

For the classification using the MERIS VI dataset, the chlorophyll range, MTCI in the high chlorophyll and low chlorophyll season and MGVI in the high chlorophyll and low chlorophyll season, were computed and used as discriminatory variables (figure 2). The chlorophyll range was defined as the difference between the MTCI/MGVI ratio estimates derived for August and September, respectively, from

$$
\mathrm{C}_{\mathrm{A}-\mathrm{S}}=\frac{\mathrm{MTCI}_{\mathrm{A}}}{\mathrm{MGVI}_{\mathrm{A}}}-\frac{\mathrm{MTCI}_{\mathrm{S}}}{\mathrm{MGVI}_{\mathrm{S}}}
$$

where $\mathrm{C}_{\mathrm{A}-\mathrm{S}}$ is the chlorophyll range and the subscripts identify the month of data acquisition.

An initial set of classifications was undertaken using a discriminant analysis. In these, each case was allocated to the class with which it had the highest posterior probability of membership. Since such probabilistic classification analyses may not always be appropriate, a further set of classifications was undertaken with a support vector machine (SVM). SVMs have attracted the attention of the remote sensing community for supervised image classification applications (Brown et al. 1999, Huang et al. 2002, Halldorsson et al. 2003). The mathematical background to SVM classification is discussed extensively in the literature (e.g. Huang et al. 2002, Foody and Mathur 2004). A key attraction of SVM for image classification is that comparative studies have shown that SVM may classify remotely sensed data more accurately than other more commonly used classifiers (Huang et al. 2002, Pal and Mather 2003, Foody and Mathur 2004). Two parameters, one controlling the balance between the desire to maximize the margin between the classes against the term that penalizes cases on the wrong side of the classifier's decision boundary $(C)$ and the other to control the width of the Gaussian kernel used $(\gamma)$, need to be defined for a SVM classification. Here, a range of parameter settings were evaluated and the set that yielded the highest classification accuracy reported. This approach was adopted in order to indicate the greatest potential accuracy achievable.

For comparative purposes, the same training and testing sites were used in the two sets of classifications (MERIS spectral dataset and MERIS VI dataset). Classifications derived using both datasets were compared to evaluate the relative value of the two information sources for mapping the land cover of the study area. In all cases, classification accuracy was expressed as the percentage of testing cases correctly classified (overall accuracy). The statistical significance of differences in the accuracy of the classifications derived was assessed using a McNemar test, without correction for continuity, for related samples (Foody 2004). All testing was undertaken at the $95 \%$ level of confidence. Interpretation of the test results is based on the $Z$ statistic, with, for example, a value $Z \geqslant|1.96|$ indicating a statistically significant difference in accuracy at the $95 \%$ confidence level. 
Table 2. Wilks' lambda coefficients derived from MERIS data acquired in August.

\begin{tabular}{clc}
\cline { 2 - 3 } & Variable & Wilks' lambda \\
\cline { 2 - 3 } & NDVI & .106 \\
& B13 & .155 \\
$\mathbf{0 0}$ & B12 & .156 \\
& B10 & .160 \\
& MGVI & .169 \\
& MTCI & .169 \\
& B14 & .173 \\
& Chlorophyll concentration & .254 \\
& B9 & .274 \\
& B5 & .350 \\
& B6 & .365 \\
& B8 & .372 \\
& B7 & .373 \\
& B4 & .423 \\
& B3 & .446 \\
& B2 & .468 \\
& B1 & .488 \\
\hline
\end{tabular}

\section{Results and discussion}

The discriminating ability of the MERIS spectral dataset and MERIS VI dataset was indicated by the magnitude of the Wilks' lambda coefficient derived from the discriminant analyses (tables 2-4). It was evident for both the August and September datasets that a vegetation index provided the greatest discriminating information. Moreover, in relation to the MERIS spectral dataset, discriminating ability appeared to be related positively to wavelength. The rank order of the discriminating variables and level of spectral separability of the classes, however, appeared to vary with time. For example, data acquired in August appeared to provide a greater degree of discrimination than those acquired in September. In addition, while the NDVI was the most discriminating variable in August, the

Table 3. Wilks' lambda coefficients derived from MERIS data acquired in September.

\begin{tabular}{lc}
\hline Variable & Wilks' lambda \\
\hline MTCI & .166 \\
B14 & .235 \\
B13 & .240 \\
B12 & .262 \\
B10 & .267 \\
NDVI & .280 \\
MGVI & .348 \\
B9 & .437 \\
Chlorophyll concentration & .493 \\
B5 & .568 \\
B6 & .585 \\
B7 & .596 \\
B8 & .596 \\
B4 & .630 \\
B3 & .642 \\
B2 & .649 \\
B1 & .654 \\
\hline
\end{tabular}


Table 4. Wilks' lambda coefficients derived from the combined August and September MERIS datasets.

\begin{tabular}{lc}
\hline Variable & Wilks' lambda \\
\hline NDVI - August & .106 \\
B13 - August & .155 \\
B12 - August & .156 \\
B10 - August & .160 \\
MTCI - September & .166 \\
MGVI - August & .169 \\
MTCI - August & .169 \\
B14 - August & .173 \\
B14 - September & .235 \\
B13 - September & .240 \\
Chlorophyll concentration - August & .254 \\
B12 - September & .262 \\
B10 - September & .267 \\
B9 - August & .274 \\
NDVI - September & .280 \\
MGVI - September & .348 \\
B5 - August & .350 \\
B6 - August & .365 \\
B8 - August & .372 \\
B7 - August & .373 \\
B4 - August & .423 \\
B9 - September & .437 \\
B3 - August & .446 \\
B2 - August & .468 \\
B1 - August & .488 \\
Chlorophyll concentration - September & .493 \\
Chlorophyll range & .521 \\
B5 - September & .568 \\
B6 - September & .585 \\
B7 - September & .596 \\
B8 - September & .596 \\
B4 - September & .630 \\
B3 - September & .642 \\
B2 - September & .649 \\
B1 - September & .654 \\
\hline & \\
&
\end{tabular}

MTCI provided the greatest degree of discrimination in September. With the data for the two months combined, the vegetation indices, especially the MTCI, were amongst the most discriminating variables (table 4).

Using data acquired for each month individually and combined, land cover maps of the study area were produced using a stepwise discriminant analysis. For the August dataset, nine spectral wavebands were selected from the spectral dataset for inclusion in the classification and used to derive a map with an estimated accuracy of $66.7 \%$ (table 5). Only five spectral wavebands were selected from the corresponding analysis of the data acquired in September and, as expected from the separability analyses, the derived land cover map was less accurate than that derived from the data acquired in August, with an accuracy of 55.9\% (table 6). For all classes except grassland, classification accuracy was lower in the September than in the August dataset. Combining the MERIS spectral dataset acquired in August and September resulted in an increase in class separability, and hence map accuracy. 


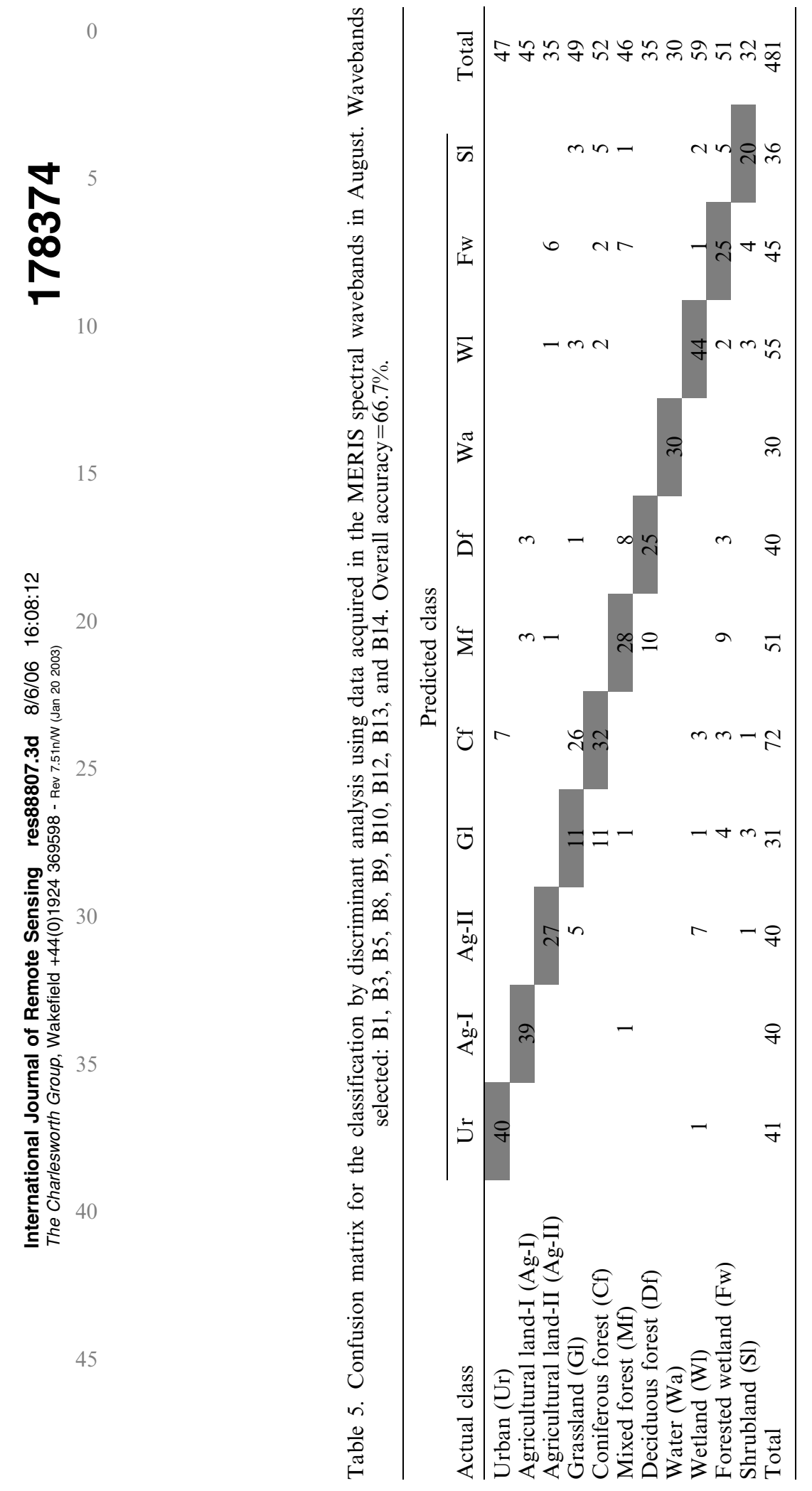




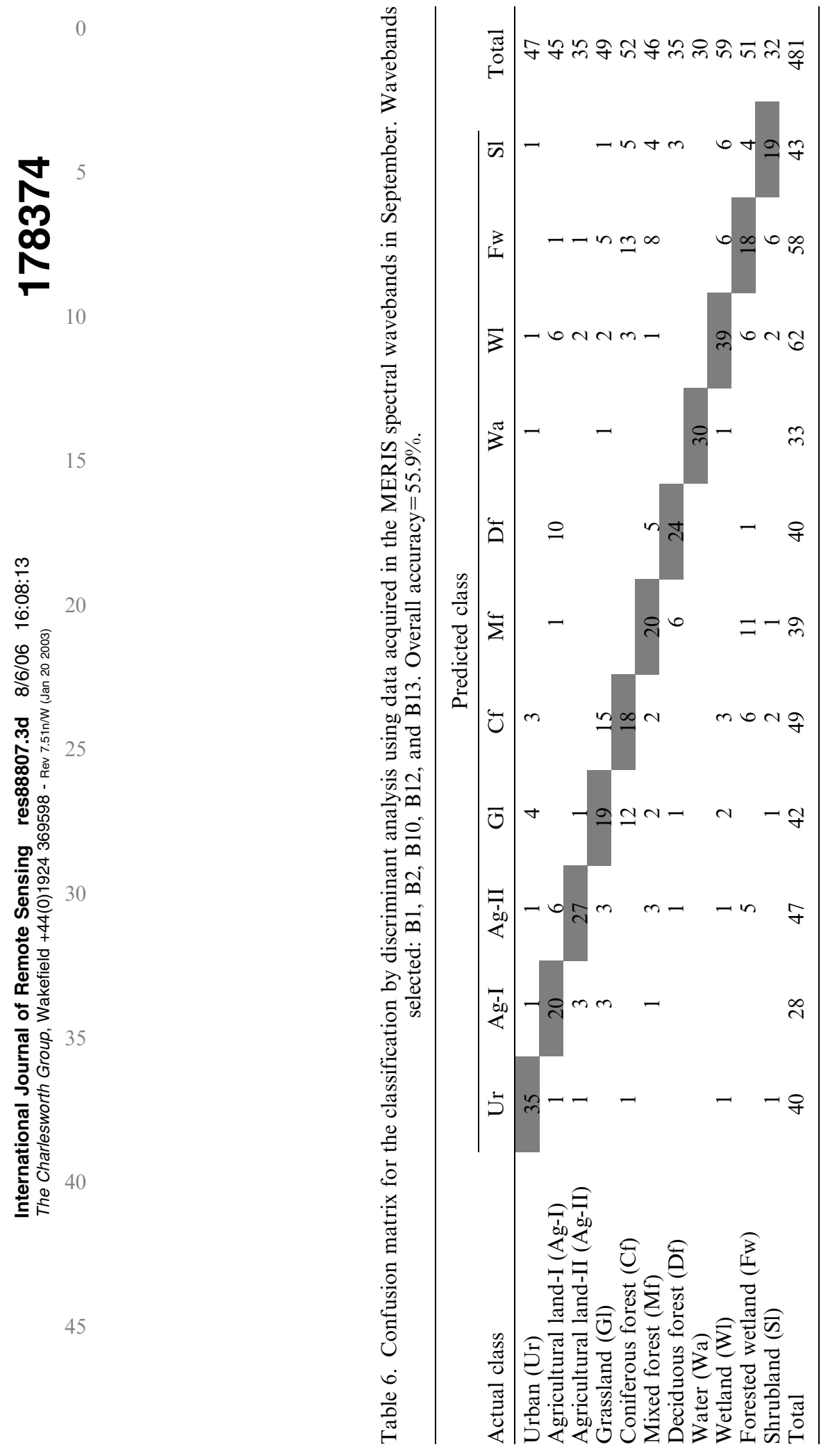


$0 \quad$ With the eleven selected spectral bands, the discriminant analysis classified the land cover study area to an accuracy of $69.0 \%$ (table 7 ).

Using the set of wavebands selected in the discriminant analyses, the classifications were repeated using the SVM. The SVM was able to classify the data for each month more accurately than was possible with discriminant analysis, with accuracies of $67.6 \%$ and $61.3 \%$ derived for the classification of the data acquired in August and September, respectively (tables 8 and 9). The main difference was in relation to the September dataset, and most notably the deciduous forest class. The classification derived from the combined use of the August and September datasets was, however, of comparable accuracy to that derived from the corresponding discriminant analysis (table 10).

The results of the discriminant analysis indicated an ability to classify land cover to a moderate level of accuracy. However, since the size of the training set required is typically a function of the number of discriminating variables, the provision of the data acquired in all thirteen available wavebands as discriminating variables may 15 necessitate the use of a large training set. The potential of the MERIS VI dataset for classification, which may allow a reduction in the size of the training set required, was assessed through classifications by discriminant analysis and SVM. Discriminant analysis yielded a classification with an overall accuracy of $67.2 \%$ (table 11), marginally, but insignificantly $(Z=-0.384)$, different from the comparable classification based on the MERIS spectral dataset (table 7). The SVM classification was significantly more accurate than that derived from the discriminant analysis $(Z=2.36$ ), with an overall accuracy of $73.2 \%$ (table 12 ). In general, the accuracy of each class from the producer's perspective was higher in the SVM classification, except for three classes for which there were very small decreases in accuracy associated with no more than four pixels. Critically, for classification by SVM, the use of the MERIS VI dataset rather than the MERIS spectral dataset resulted in a $4.4 \%$ increase in accuracy, although the difference was (marginally) insignificant $(Z=1.86)$. The MERIS VI dataset, therefore, appears able to provide at least a comparable, if not increased, ability to discriminate the land cover classes relative to that associated with the MERIS spectral dataset, and have great potential for use in land cover classification. It is possible that data acquired at different dates, especially in the high chlorophyll season, may provide further discrimination and increase in classification accuracy.

\section{Conclusions}

The study highlighted the potential of MERIS data, and especially the MERIS VI dataset, for use as discriminating variables in land cover classification. The ability to separate eleven broad land cover classes in Wisconsin using MERIS data acquired on two dates was assessed. The MERIS VI dataset provided a high degree of interclass separability, more so than many of the spectral wavebands. Separability and classification accuracy were also observed to vary between dates, being higher with data acquired in August rather than September. Using together the data acquired in each month resulted in an increase in classification accuracy. It is possible that the use of data acquired earlier in the growing season may further enhance class separability, and this is an issue that could be addressed in future research.

The highest accuracy was obtained using the MERIS VI dataset with a SVM, yielding an accuracy of $73.2 \%$. MERIS vegetation index data are now readily accessible from ESA as a fine spatial resolution $(300 \mathrm{~m})$ level 2 product with a 


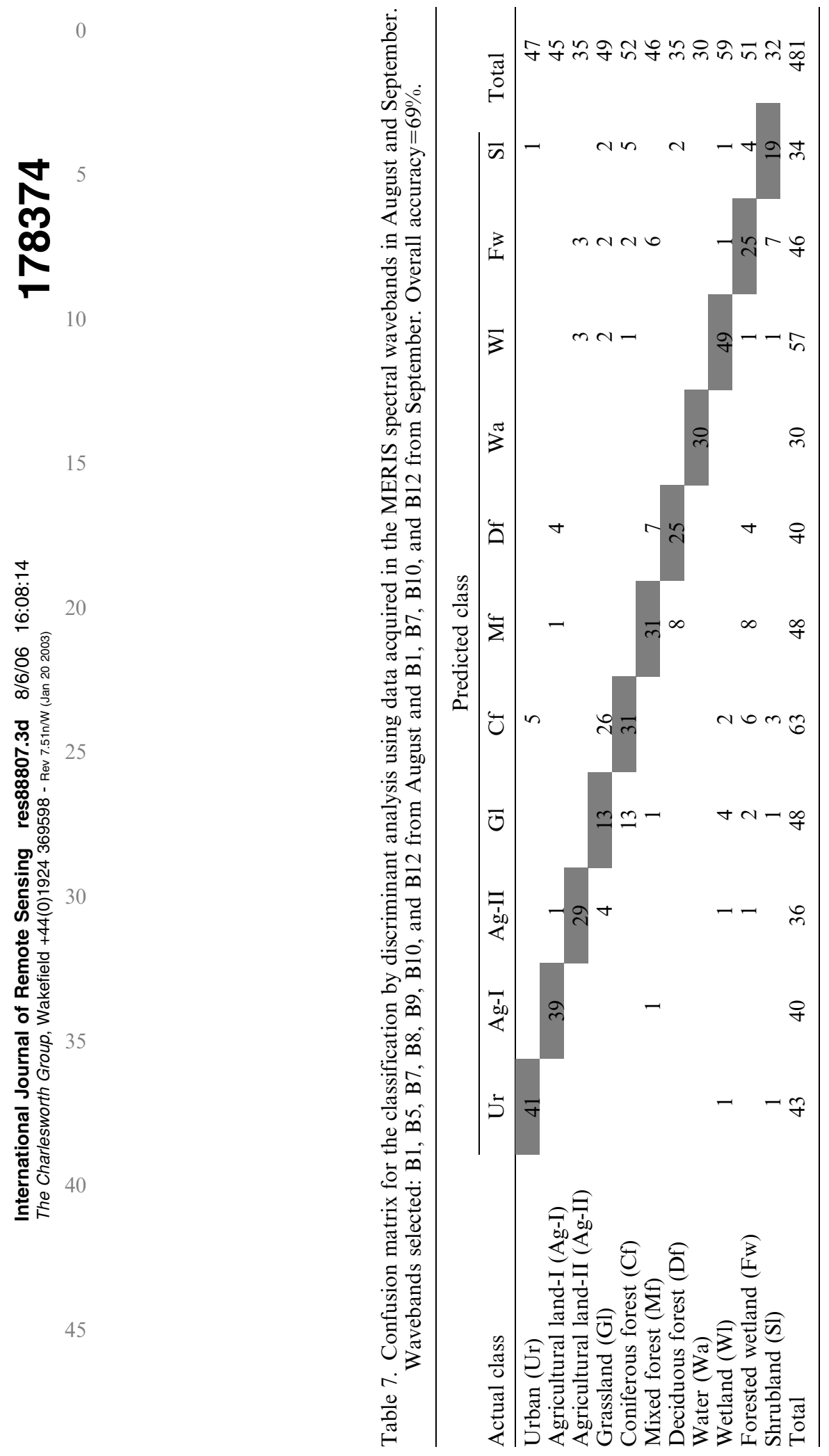




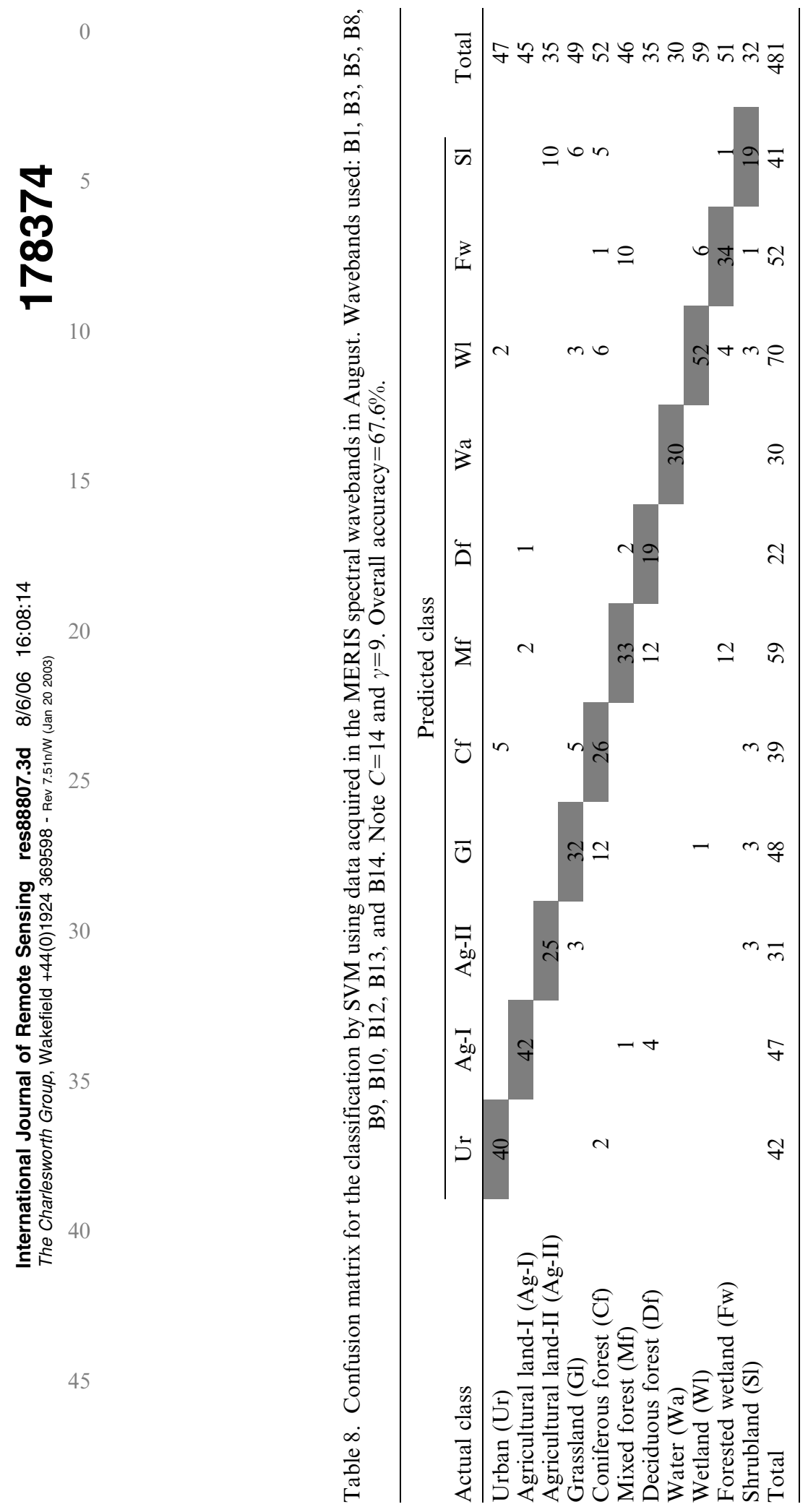




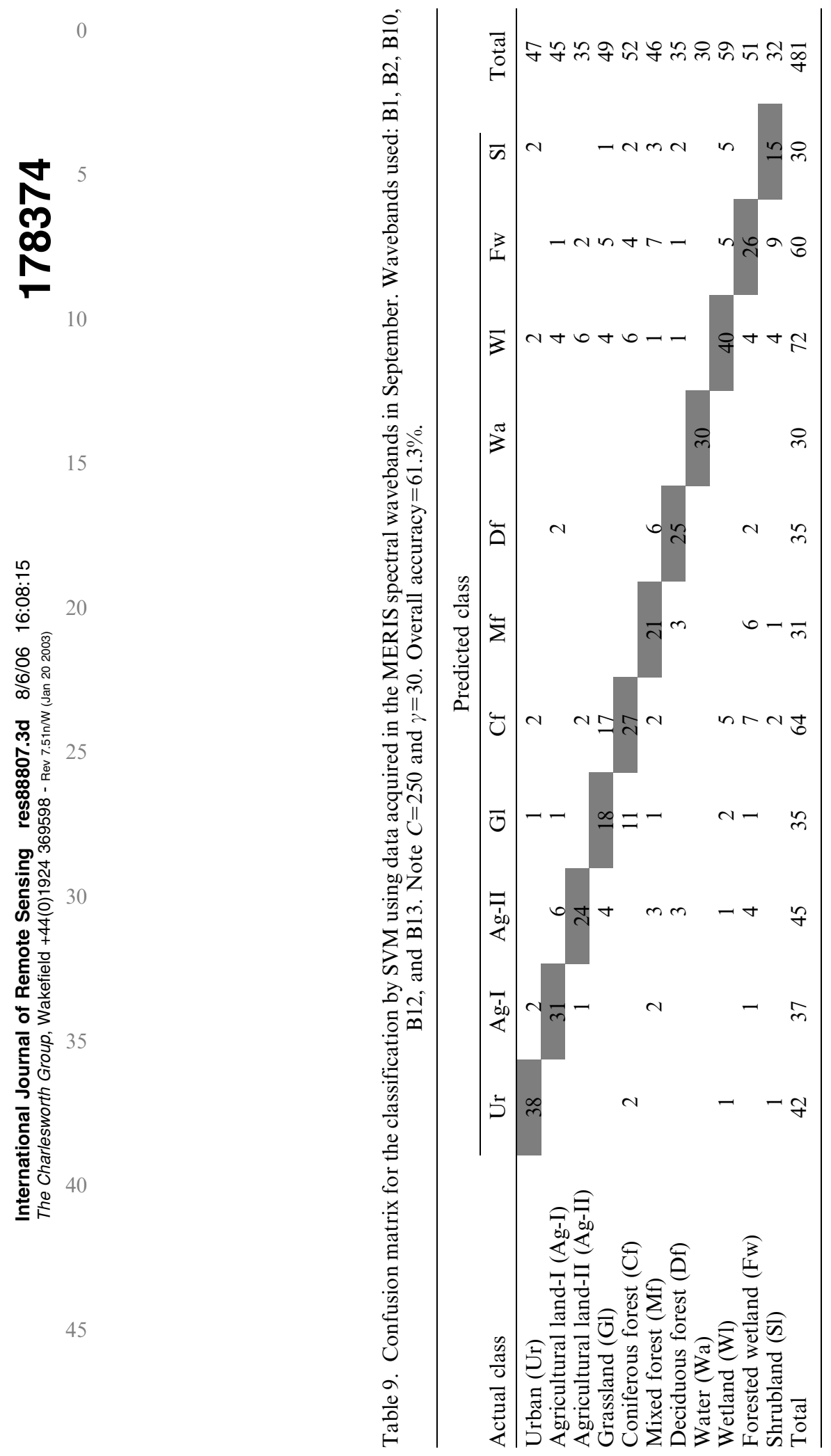




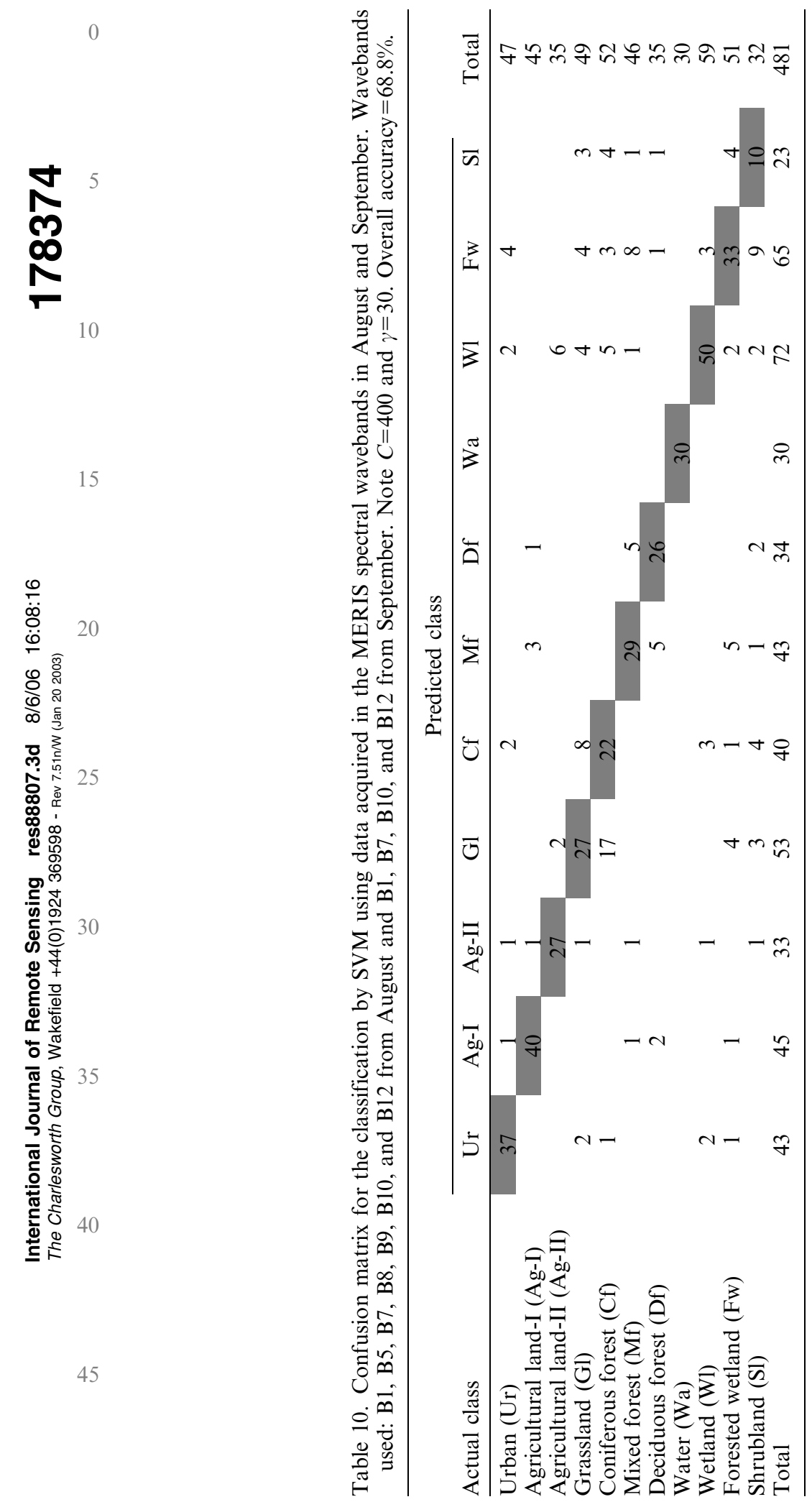




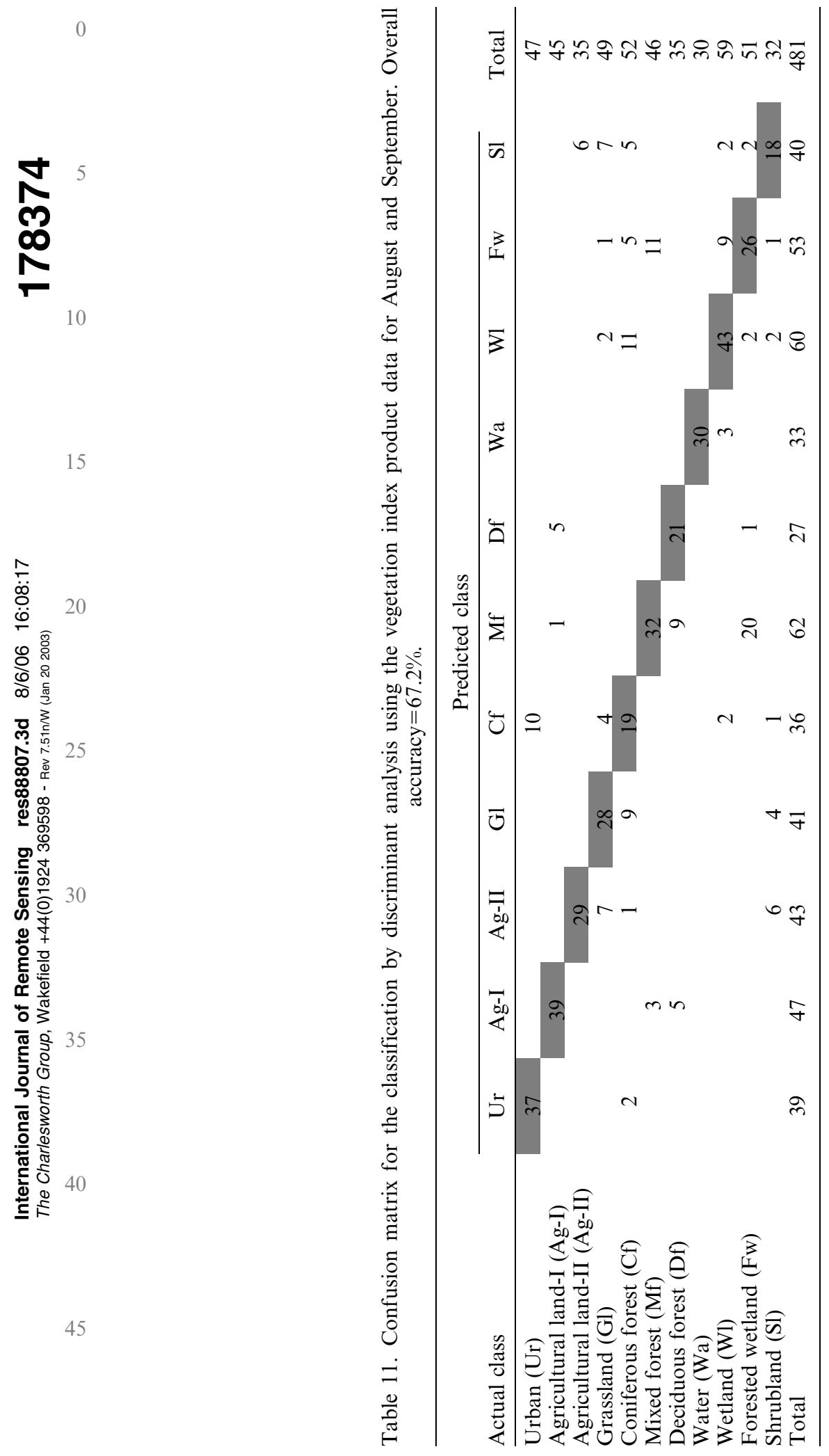




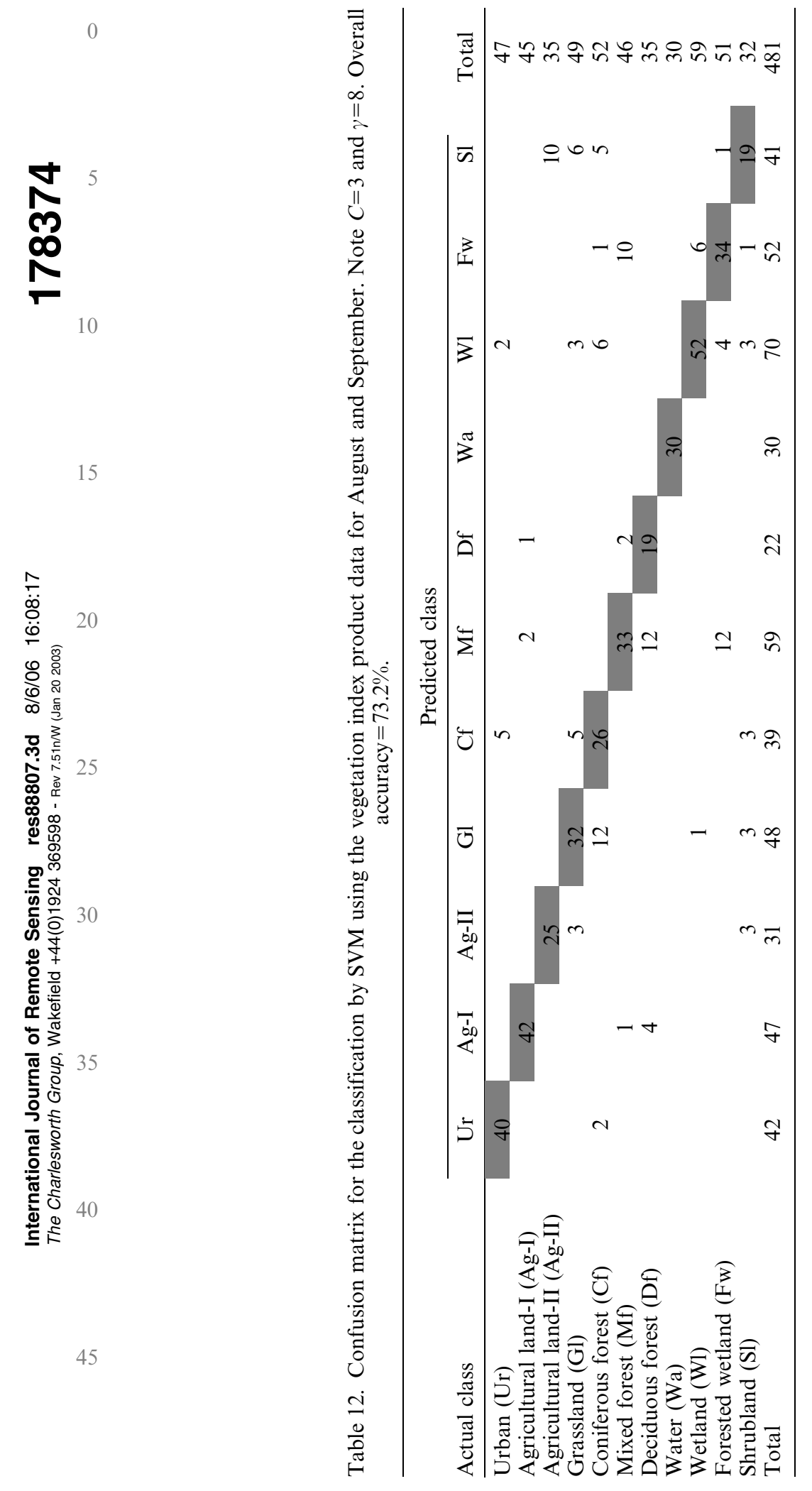


potential for reducing both volume of data and size of training sets used in land cover classification. It is, therefore, anticipated that MERIS vegetation index data will be used increasingly for mapping land cover at regional- to global-scale.

\section{Acknowledgements}

The authors wish to thank the Worldwide University Network (WUN) for providing funding to JD through a Global Exchange Programme to undertake part of this study at the University of Wisconsin-Madison; the Department of Natural Resources at Wisconsin for WISCLAND data; ESA for MERIS data (as a part of a Principal Investigatorship to PJC), and the British Council for provision of a scholarship to support AM's research at the University of Southampton while on leave from the Punjab Remote Sensing Centre, India. The SVM used was the BSVM (version 2.01) developed by Hsu and Lin at the National Taiwan University.

\section{$15 \quad$ References}

Achard, F. and Estreguil, C., 1995, Forest classification of Southeast Asia using NOAA AVHRR data. Remote Sensing of Environment, 54, pp. 198-208.

Anderson, G.L., Hanson, J.D. and HaAs, R.H., 1993, Evaluating Landsat Thematic Mapper-derived vegetation indexes for estimating above-ground biomass on semiarid rangelands. Remote Sensing of Environment, 45, pp. 165-175.

Baret, F. and Guyot, G., 1991, Potentials and limits of vegetation indexes for LAI and APAR assessment. Remote Sensing of Environment, 35, pp. 161-173.

Benedetti, R., Rossini, P. and TAddeI, R., 1994, Vegetation classification in the middle Mediterranean area by satellite data. International Journal of Remote Sensing, 15, pp. 583-596.

Benediktsson, J.A., Swain, P.H. and Ersoy, O.K., 1990, Neural network approaches versus statistical-methods in classification of multisource remote-sensing data. IEEE Transactions on Geoscience and Remote Sensing, 28, pp. 540-552.

Brown, M., Gunn, S.R. and Lewis, H.G., 1999, Support vector machines for optimal classification and spectral unmixing. Ecological Modelling, 120, pp. 167-179.

Cinlar, J., 2000, Land cover mapping of large areas from satellites: status and research priorities. International Journal of Remote Sensing, 21, pp. 1093-1114.

Clark, R.N., King, T.V.V., Ager, C. and Swayze, G.A., 1995, Initial vegetation species and senescence/stress indicator mapping in the San Luis Valley, Colorado, using imaging spectrometer data. In AVIRIS Airborne Geoscience Workshop Proceedings, Pasadena, California (Pasadena: Jet Propulsion Laboratory).

Clevers, J.G.P.W., 1988, The derivation of a simplified reflectance model for the estimation of leaf area index. Remote Sensing of Environment, 35, pp. 53-70.

Curran, P.J. and Steele, C.M., 2005, MERIS: the re-branding of an ocean sensor. International Journal of Remote Sensing, 26, pp. 1781-1798.

Curran, P.J., Windham, W.R. and Gholz, H.L., 1995, Exploring the relationship between reflectance red edge and chlorophyll concentration in slash pine leaves. Tree Physiology, 15, pp. 203-206.

Curran, P.J., Dungan, J.L. and Peterson, D.L., 2001, Estimating the foliar biochemical concentration of leaves with reflectance spectrometry: testing the Kokaly and Clark methodologies. Remote Sensing of Environment, 76, pp. 349-359.

DAsh, J. and CuRRAN, P.J., 2004, The MERIS Terrestrial Chlorophyll Index. International Journal of Remote Sensing, 25, pp. 5003-5013.

DATT, B., 1998, Remote sensing of chlorophyll a, chlorophyll b, chlorophyll a $+\mathrm{b}$, and total carotenoid content in Eucalyptus leaves. Remote Sensing of Environment, 66, pp. $111-121$. 
0 Daughtry, C.S.T., Walthall, C.L., Kim, M.S., Brown de Colstoun, E. and MCMurtrey III, J.E., 2000, Estimating corn leaf chlorophyll concentration from leaf and canopy reflectance. Remote Sensing of Environment, 74, pp. 229-239.

DeFries R.S. and Townshend, J.R.G., 1994, NDVI-derived land-cover classifications at a global-scale. International Journal of Remote Sensing, 15, pp. 3567-3586.

Foody, G.M., 2002, Status of land cover classification accuracy assessment. Remote Sensing of Environment, 80, pp. 185-201.

Foody, G.M., 2004, Thematic map comparison: evaluating the statistical significance of differences in classification accuracy. Photogrammetric Engineering and Remote Sensing, 70, pp. 627-633.

Foody, G.M. and MATHUR, A., 2004, A relative evaluation of multiclass image classification by support vector machines. IEEE Transactions on Geoscience and Remote Sensing, 42, pp. 1335-1343.

Friedl, M.A. and Brodley, C.E., 1997, Decision tree classification of land cover from remotely sensed data. Remote Sensing of Environment, 61, pp. 399-409.

Gaston, G.G., Jackson, P.L., Vinson, T.S., Kolchugina, T.P., Вотch, M. and КовaK, K., 1994, Identification of carbon quantifiable regions in the former Soviet-Union using unsupervised classification of AVHRR global vegetation index images. International Journal of Remote Sensing, 15, pp. 3199-3221.

Gitelson, A.A. and MerzlyaK, M.N., 1998, Remote sensing of chlorophyll concentration in higher plant leaves. Advances in Space Research, 22, pp. 689-692.

Gobron, N., Pinty, B., Verstraete, M. and Govaerts, Y., 1999, The Meris global vegetation index (MGVI): description and preliminary application. International Journal of Remote Sensing, 20, pp. 1917-1927.

Gobron, N., Mélin, F., Pinty, B., Taberner, M. and Verstraete, M.M., 2003, MERiS global vegetation index: evaluation and performance. In Proceeding of MERIS User Workshop, 10-14 November, Frascati, Italy (Frascati: ESA).

Halldorsson, G.H., Benediktsson, J.A. and Sveinsson, J.R., 2003, Support vector machines in multisource classification. In Proceedings of IEEE Remote Sensing and Geosciences Conference, 21-25 July, Toulouse, France (New York: IEEE).

Han, K.S., Champeaux, J.L. and Roujean, J.L., 2004, A land cover classification product over France at $1 \mathrm{~km}$ resolution using SPOT4/VEGETATION data. Remote Sensing of Environment, 92, pp. 52-66.

Hansen, M.C., Defries, R.S., Townshend, J.R.G. and Sohlberg, R., 2000, Global land cover classification at $1 \mathrm{~km}$ spatial resolution using a classification tree approach. International Journal of Remote Sensing, 21, pp. 1331-1364.

Hill, R.A. and Foody, G.M., 1994, Separability of tropical rain-forest types in the Tambopata-Candamo reserved zone, Peru. International Journal of Remote Sensing, 15, pp. 2687-2693.

Hirata, M., Koga, N., Shinjo, H., Fujita, H., Gintzburger, G. and Miyazaki, A., 2001, Vegetation classification by satellite image processing in a dry area of north-eastern Syria. International Journal of Remote Sensing, 22, pp. 507-516.

Huang, C., Davis, L.S. and Townshend, J.R.G., 2002, An assessment of support vector machines for land cover classification. International Journal of Remote Sensing, 23, pp. 725-749.

Huete, A.R., 1988, A soil-adjusted vegetation index (SAVI). Remote Sensing of Environment, 25, pp. 295-309.

Huete, A., Didan, K., Miura, T., Rodriguez, E.P., Gao, X. and Ferreira, L.G., 2002, Overview of the radiometric and biophysical performance of the MODIS vegetation indices. Remote Sensing of Environment, 83, pp. 195-213.

Justice, C.O., Townshend, J.R.G. and Choudhury, B.J., 1989, Comparison of AVHRR and SMMR data for monitoring vegetation phenology on a continental scale. International Journal of Remote Sensing, 10, pp. 1607-1632. 
KAUfman, Y.J. and TANRÉ, D., 1992, Atmospherically resistant vegetation index (ARVI) for EOS-MODIS. IEEE Transactions on Geoscience and Remote Sensing, 30, pp. 261-270.

Krishnaswamy, J., Kiran, M.C. and Ganeshaiah, K.N., 2004, Tree model based ecoclimatic vegetation classification and fuzzy mapping in diverse tropical deciduous ecosystems using multi-season NDVI. International Journal of Remote Sensing, 25, pp. $1185-1205$.

Latifovic, R., Zhu, Z.L., Cihlar, J., GiRi, C. and Olthof, I., 2004, Land cover mapping of north and central America - global land cover 2000. Remote Sensing of Environment, 89, pp. 116-127.

LI, P.J. and Moon, W.M., 2004, Land cover classification using MODIS-ASTER airborne simulator (MASTER) data and NDVI: a case study of the Kochang area, Korea. Canadian Journal of Remote Sensing, 30, pp. 123-136.

Lillesand, T.M., Chipman, J.W., Nagel, D.E., Reese, H.M., Bobo, M.R. and Goldmann, R.A., 1998, Upper Midwest Gap Analysis Program image processing protocol. Environmental Management Technical Center Report EMTC-98-G001, Environmental Management Technical Center, US Geological Survey, Onalaska, WI.

15 LlOYD, D., 1990, A phenological classification of terrestrial vegetation cover using shortwave vegetation index imagery. International Journal of Remote Sensing, 11, pp. 2269-2279.

Lobo, A., Marti, J.J.I. and Gimenezcassina, C.C., 1997, Regional scale hierarchical classification of temporal series of AVHRR vegetation index. International Journal of Remote Sensing, 18, pp. 3167-3193.

Loveland, T.R., Reed, B.C., Brown, J.F., Ohlen, D.O., Zhu, Z., Yang, L. and Merchant, J.W., 2000, Development of a global land cover characteristics database and IGBP DISCover from $1 \mathrm{~km}$ AVHRR data. International Journal of Remote Sensing, 21, pp. 1303-1330.

Mariotti, M., Ercoli, L. and Masoni, A., 1996, Spectral properties of iron-deficient corn and sunflower leaves. Remote Sensing of Environment, 58, pp. 282-288.

Mather, P.M., 2004, Computer Processing of Remotely-Sensed Images: An Introduction (Third Edition) (Chichester: John Wiley \& Sons).

Myneni, R.B., Maggion, S., Iaquinto, J., Privette, J.L., Gobron, N., Pinty, B., Kimes, D.S., Verstraete, M.M. and Williams, D.L., 1995, Optical remote-sensing of vegetation - modelling, caveats, and algorithms. Remote Sensing of Environment, 51, pp. 169-188.

Nemani, R., Pierce, L.L., Running, S. and Band, L., 1993, Forest ecosystem process at the watershed scale: sensitivity to remotely-sensed leaf area index estimates. International Journal of Remote Sensing, 14, pp. 2519-2534.

O’Neill, A.L., Kupiec, J.A. and CurRan, P.J., 2002, Biochemical and reflectance variation throughout a Stika spruce canopy. Remote Sensing of Environment, 80, pp. 134-142.

PAL, M. and MAther, P.M., 2003, An assessment of the effectiveness of decision tree methods for land cover classification. Remote Sensing of Environment, 86, pp. 554-565.

Peterson, D.L., Aber, J.D., Matson, P.A., Card, D.H., Swanberg, N., Wessman, C. and SpANNER, M., 1988, Remote sensing of forest canopy and leaf biochemical content. Remote Sensing of Environment, 24, pp. 85-108.

Pinar, A. and Curran, P.J., 1996, Grass chlorophyll and the reflectance red edge. International Journal of Remote Sensing, 17, pp. 351-357.

Pinty, B. and Verstraete, M.M., 1992, GEMI - a nonlinear index to monitor global vegetation from satellites. Vegetatio, 101, pp. 15-20.

45 RASt, M., BÉzy, J.L. and BruZzi, S., 1999, The ESA medium resolution imaging spectrometer MERIS - a review of the instrument and its mission. International Journal of Remote Sensing, 20, pp. 1681-1702.

Reese, H.M., Lillesand, T.M., Nagel, D.E., Stewart, J.S., Goldmann, R.A., Simmons, T.E., Chipman, J.W. and Tessar, P.A., 2002, Statewide land cover 
derived from multiseasonal Landsat TM data - a retrospective of the WISCLAND project. Remote Sensing of Environment, 82, pp. 224-237.

Richardson, A.L. and Wiegand, C.L., 1977, Distinguishing vegetation from soil background information. Photogrammetric Engineering and Remote Sensing, 43, pp. $1541-1552$.

Running, S.W., Loveland, T.R., Pierce, L.L., Nemani, R. and Hunt, E.R., 1995, A remote-sensing based vegetation classification logic for global land-cover analysis. Remote Sensing of Environment, 51, pp. 39-48.

Smith, G.M. and Curran, P.J., 1992, Exploring the remote sensing of foliar biochemical concentration with AVIRIS data. In AVIRIS Airborne Geoscience Workshop Proceedings, Pasadena, California, pp. 50-52 (Pasadena: Jet Propulsion Laboratory).

Smith, P.M., Kalluri, S.N.V., Prince, S.D. and Defries, R., 1997, The NOAA/NASA pathfinder AVHRR 8-km land data set. Photogrammetric Engineering and Remote Sensing, 63, pp. 12-40.

Steele, B.M., 2000, Combining multiple classifiers: an application using spatial and remotely sensed information for land cover type mapping. Remote Sensing of Environment, 74, pp. 545-556.

Treitz, P. and Rogan, J., 2004, Remote sensing for mapping and monitoring land-cover and land-use change. Progress in Planning, 61, pp. 267-279.

Tucker, C.J., Townshend, J.R.G. and GofF, T.E., 1985, African land cover classification using satellite data. Science, 227, pp. 369-375.

Verstraete, M.M. and Pinty, B., 1996, Designing optimal spectral indexes for remote sensing applications. IEEE Transactions on Geoscience and Remote Sensing, 34, pp. 1254-1265.

Verstraete, M.M., Pinty, B. and Curran, P.J., 1999, MeRiS potential for land application. International Journal of Remote Sensing, 20, pp. 1747-1756.

WiDNR, 1998, User's Guide to WISCLAND Land Cover Data. Wisconsin Department of 4 Natural Resources Report. Available online at: http://www.dnr.state.wi.us/maps/gis/ datalandcover.html (accessed XX month year).

Wilkinson, G.G., 1996, Classification algorithms - where next? In Soft Computing in Remote Sensing Data Analysis, E. Binaghi, P.A. Brivio and A. Rampini (Eds), pp. 93-99 (Singapore: World Scientific).

Wilkinson, G.G., 2005, Results and implications of a study of fifteen years of satellite image classification experiments. IEEE Transactions on Geoscience and Remote Sensing, 43, pp. 433-440. 